\title{
CARACTERIZAÇÃO DOS CASOS DE VIOLENCIA CONTRA IDOSOS NO MUNICÍPIO DE SANTA MARIA
}

\author{
Gabriele de Andrades Pippi ${ }^{1}$ \\ Fernanda Beheregaray Cabral ${ }^{2}$ \\ Marinês Tambara Leite ${ }^{3}$ \\ Leila Mariza Hildebrandt ${ }^{4}$ \\ Isabel Cristina Pacheco van der Sand ${ }^{5}$
}

resumo

Este estudo teve o objetivo de caracterizar os casos de violência contra os idosos no município de Santa Maria/RS ocorridos durante o período de 2014, por meio da coleta de dados encontrados nos registros policiais da delegacia de proteção ao idoso. Trata-se de uma pesquisa documental, descritiva, transversal e retrospectiva.

\footnotetext{
1 Graduada em Terapia ocupacional. Especialista em Gestão de Organização Pública em Saúde. E-mail: gabi.pippi@hotmail.com.

2 Graduada em Enfermagem. Doutora em Ciências. Professora Adjunto da Universidade Federal de Santa Maria/Campus Palmeira das Missões. E-mail: cabralfernandab@gmail.com.

3 Graduada em Enfermagem. Doutora em Gerontologia Biomédica. Professora Associada da Universidade Federal de Santa Maria/Campus Palmeira das Missões. E-mail: tambaraleite@yahoo.com.br 4 Graduada em Enfermagem. Doutora em Ciências. Professora Adjunto da Universidade Federal de Santa Maria/Campus Palmeira das Missões. E-mail: leilahildebrandt@yahoo.com.br.

5 Graduada em Enfermagem. Doutora em Ciências. Professora Aposentada pela Universidade Federal de Santa Maria/Campus Palmeira das Missões. E-mail: isabelvan@gmail.com.
} 
Os dados foram processados no software SPSS, versão 15.0. Constatou-se que as vítimas mulheres são superiores em número. A idade dominante é entre 60 e 70 anos, a escolaridade que prevalece é o ensino fundamental e a maioria da amostra é casada. Já em relação aos agressores, verificou-se que predomina o sexo masculino, com idade entre 40 e 60 anos e sem vínculos familiares com as vítimas. $\bigcirc$ tipo de violência mais praticada foi a ameaça, seguida de lesão corporal e perturbação da tranquilidade. Desta forma, percebe-se que, mesmo com a garantia de leis, como a Constituição Federal 1988, a Política Nacional do Idoso e o Estatuto do Idoso que amparam os idosos, a situação da violência ainda é presente. É necessário adotar medidas para reverter essa situação e promover um envelhecimento com qualidade.

palavras-chave

Idosos. Violência. Maus Tratos ao Idoso. Políticas Públicas.

\section{Introdução}

O envelhecimento populacional é um fenômeno que vem ocorrendo pelo aumento da expectativa de vida e diminuição da taxa de fecundidade, associados a melhores condições de vida e às transformações socioeconômicas (SOUZA; MINAYO, 2010; MASCARANHAS et al., 2012; GUIMARÃES et al., 2016). Com a elevação no número de idosos, surgem novas necessidades em vários setores da sociedade, entre elas cita-se: político, econômico, social, previdenciário, cultural e saúde; além daquelas de ordem privada, como as relativas à família. Assim, conjuntamente com o envelhecimento populacional, emergem outras problemáticas, como aumento das doenças crônicas degenerativas, complicações decorrentes de acidentes por quedas, estigma social, preconceito e situações de violência e maus tratos, cujo enfrentamento demanda ações públicas intersetoriais e, em âmbito privado, a corresponsabilização familiar (MASCARENHAS et al., 2012; GUIMARÃES et al., 2016). Esses contextos incidem diferentemente no cotidiano da pessoa idosa, com possibilidade de potencializar vulnerabilidades já instituídas e/ou outras que podem repercutir na saúde dessa população.

A Organização Mundial da Saúde (OMS) caracteriza violência contra o idoso como ação ou omissão intencional ou involuntária, de natureza física e/ou psicológica, envolvendo maus-tratos de ordem financeira e/ou material. As situações de violência e os maus-tratos à pessoa idosa abrangem abusos 
físicos, psicológicos, sexuais, financeiros, abandono, negligências praticadas por familiares, profissionais ou pela população em geral, e autonegligência (OMS, 2002; SOUZA; MINAYO, 2010; PINHEIRO et al., 2011).

Dentre as diferentes tipologias de maus-tratos, Souza e Minayo (2010) destacam: violência física como referente ao uso da força física para ferir, provocar dor, incapacidade ou morte, ou para compelir o idoso a fazer o que não deseja; violência psicológica são agressões verbais ou gestuais com a finalidade de aterrorizar, humilhar, restringir a liberdade ou isolar o idoso do convívio social; violência sexual é referente aos atos ou jogos sexuais de caráter homo ou heterorrelacional, que utilizam pessoas idosas visando obter excitação, relação sexual ou práticas eróticas por meio de aliciamento, violência física ou ameaças; violência financeira ou econômica consiste na exploração imprópria, ilegal ou não, consentida dos bens financeiros e patrimoniais do idoso. Além destas, o abandono também é relacionado aos maus-tratos contra idosos, que consiste na ausência ou deserção dos responsáveis governamentais, institucionais ou familiares de prestarem socorro a um idoso que necessite de proteção; como também a negligência, a qual se refere à recusa ou omissão de cuidados necessários à pessoa idosa, por parte da família, responsáveis ou instituições (SOUZA; MINAYO, 2010).

Ainda, nesse sentido, as diferentes situações de maus-tratos causam sofrimento, perda de direitos humanos e redução da qualidade de vida da pessoa idosa, com potencial para produzir processos de adoecimento (MASCARENHAS et al., 2012; GUIMARÃES et al., 2016). Pinheiro et al. (2011) destacam que o empobrecimento da população, problemas pessoais, questões financeiras, reorganização familiar, moradia conjunta, invalidez física e mental, diminuição da capacidade funcional e cognitiva do idoso, estresse e despreparo do cuidador diante da situação de dependência e padrão prévio de relacionamento permeado pela violência são fatores que podem contribuir para contextos violentos, o que potencializa a vulnerabilidade da pessoa idosa. A convivência de idosos com pessoas mais jovens também pode gerar conflitos, tencionando essa relação de modo insustentável. Silva e Dias (2016) trazem que muitos idosos vivem com filhos adultos e o êxito dessa situação depende da qualidade do relacionamento prévio e da capacidade de ambas as gerações se comunicarem de maneira plena e honesta. Ademais, o conflito intergeracional pode ocorrer nos contextos familiar, institucional ou social e desencadear situações de violência contra o idoso.

No âmbito das políticas públicas, os direitos de cidadania da população idosa foram destacados pela Constituição Federal de 1988, ao determinar que a família, sociedade e Estado têm o dever de amparar os idosos, assegurando 
o direito à vida, à dignidade, ao bem-estar e a sua participação na comunidade. Além disso, os filhos maiores têm o dever de ajudar e amparar os pais na velhice, carência ou enfermidade e, aqueles cuja família não possui meios de prover sua manutenção, têm a garantia de um salário-mínimo de benefício mensal (BRASIL, 1988).

No cenário internacional, no ano de 2002, ocorreu a II Conferência mundial sobre envelhecimento em Madri, em que o tema da violência contra a pessoa idosa ganhou destaque e resultou no Plano de Ação Internacional sobre o Envelhecimento, sendo um de seus objetivos eliminar todas as formas de abandono, abuso e violência (BRASIL, 2003). Em âmbito nacional, em 1994, foi criada a Política Nacional do Idoso (PNI), promulgada pela Lei no 8.842, que assegura os direitos sociais da pessoa idosa, criando condições para promover sua autonomia, integração e participação efetiva na sociedade, e se destacou pela criação do Conselho Nacional do Idoso (BRASIL, 1994). Entretanto, ainda se verifica a invisibilidade da temática da violência contra a pessoa idosa na PNI, visto que, na época, a violação dos direitos da pessoa idosa não integrava as questões prioritárias atinentes à agenda das Políticas de Direitos Humanos (SOUZA; MINAYO, 2010).

Outro dispositivo legal é o Estatuto do Idoso, sancionado pela Lei no 10.741 , de 01 de outubro de 2003, que estabelece, regulamenta e protege os direitos específicos da pessoa com idade igual ou maior que 60 anos. Neste documento, o entendimento sobre violência contra o idoso abrange "qualquer ação ou omissão praticada em local público ou privado, que lhe cause morte, dano ou sofrimento físico ou psicológico" (BRASIL, 2013, p. 16). Também, estabelece diretrizes para coibir as diferentes formas de violência nesse segmento, mediante notificação compulsória dos casos de suspeita ou confirmação de violência contra a pessoa idosa, pelos serviços públicos e privados, à autoridade sanitária (BRASIL, 2013).

Em 2006, foram aprovados a Política Nacional de Saúde da Pessoa Idosa (PNPI), mediante Portaria no 2.528, de 08 de outubro de 2006 e, o documento das Diretrizes do Pacto pela Saúde que contempla o Pacto pela Vida por meio da Portaria nº 399/GM, no qual a saúde do idoso assume caráter prioritário na agenda das políticas públicas (BRASIL, 2006a; 2006b). Entretanto, a problemática da violência contra a pessoa idosa não ganhou ênfase em tais dispositivos legais. Esta temática somente ocorreu de forma mais contundente em 2007, com o Plano de ação para o enfrentamento da violência a idosos (BRASIL, 2007). No entanto, dada sua complexidade, as políticas públicas vigentes, ainda, não têm sido eficazes no que tange a proteção dessa população. 
Nesse sentido, a prevalente invisibilidade social da violência a idosos ancora-se na retórica comum a contextos violentos contra outros segmentos populacionais, de que situações dessa natureza são problemas familiares, domésticos e, portanto, de ordem privada, não sendo motivo de intervenção do Estado, tampouco um problema relevante para o campo da saúde. Porém, com a maior longevidade da população idosa, há tendência de aumentar os casos de violência, motivo pelo qual profissionais da saúde, assistência social, gestores e demais segmentos da sociedade devem estar preparados para enfrentar essa complexa situação.

Muitos casos de violência contra a pessoa idosa não são levados aos serviços de saúde e, quando o são, nem sempre são identificados, acolhidos e não notificados pelos profissionais. Isto porque, comumente, os profissionais de saúde não reconhecem situações de violência e maus-tratos como demandas de saúde, mas como um problema privado, de ordem doméstica, familiar e/ ou social, o que contribui para o sub-registro dessa problemática (MUSSE; RIOS, 2015).

Considerando o exposto, este estudo teve por objetivo caracterizar os casos de violência contra idosos de um município da região central do estado do Rio Grande do Sul.

\section{Métodos}

Este estudo trata-se de pesquisa documental, descritiva, transversal, retrospectiva, de abordagem quantitativa, cujos dados foram obtidos junto aos registros investigativos, realizados no período de janeiro a dezembro de 2014, na Delegacia de Proteção ao Idoso do município de Santa Maria/Rio Grande do Sul.

Um questionário com questões sobre características demográficas das vítimas: sexo, idade, escolaridade, estado civil; características do agressor: sexo, idade e relação com a vítima; características da ocorrência: tipo de violência denunciada foi utilizado para a coleta dos dados. Estes foram compilados, organizados e processados no software SPSS, versão 15.0. Para a análise utilizou-se a estatística descritiva e o teste Qui-Quadrado. Considerou-se como estatisticamente significativo as análises com $p<0,05$. Os resultados foram apresentados em tabelas com números absolutos e percentuais.

Atendendo às diretrizes éticas da Resolução no 466/2012 do Conselho Nacional de Saúde (CNS), a pesquisa foi autorizada pela Delegacia de Proteção ao Idoso de Santa Maria/RS e aprovada pelo Comitê de Ética em 
Pesquisa da Universidade Federal de Santa Maria (UFSM), sob o número CAAE: 48785115.4 .0000 .5346 , parecer no ${ }^{\circ}$ 1.220.977.

\section{Resultados}

No ano de 2014, dos 651 processos investigativos da Delegacia de Proteção ao Idoso de Santa Maria/RS, foram identificados 665 idosos vítimas de agressões, as quais foram perpetradas por 733 agressores. Cabe explicar que, em alguns casos, houve o registro de mais de um idoso agredido na ocasião pelo mesmo agressor, como também, a execução conjunta por mais de um agressor na violência cometida. Destaca-se que, neste estudo, não puderam ser identificados os casos de violência por repetição, ou seja, as situações em que a pessoa idosa sofreu outros episódios de maus-tratos, pelo fato de as novas ocorrências policiais não terem sido correlacionadas às anteriores. Além disso, em muitas ocasiões, a pessoa idosa sofria mais de uma tipologia de violência, mas como a classificação do delito por ocorrência ficava a critério de quem efetuava esse registro, nem sempre essas informações foram devidamente especificadas.

Tabela 1 - Distribuição dos idosos, vítimas de violência, segundo características sociodemográficas. Santa Maria/RS, 2015.

\begin{tabular}{lll}
\hline Variáveis & Frequência & Percentual \% \\
\hline Sexo & 386 & \\
Feminino & 279 & 58,0 \\
Masculino & & 42,0 \\
Faixa Etária* & 357 & \\
$60-70$ & 221 & 53,9 \\
$71-80$ & 73 & 33,4 \\
$81-90$ & 11 & 11,0 \\
$91-100$ & & 1,7 \\
\hline
\end{tabular}




\begin{tabular}{|c|c|c|}
\hline Variáveis & Frequência & Percentual \% \\
\hline \multicolumn{3}{|l|}{ Escolaridade $^{\star}$} \\
\hline Não alfabetizado & 32 & 5,1 \\
\hline Semi-alfabetizado & 24 & 3,8 \\
\hline Fundamental & 397 & 62,9 \\
\hline Médio & 94 & 14,9 \\
\hline Superior & 84 & 13,3 \\
\hline \multicolumn{3}{|l|}{ Estado Civil $^{*}$} \\
\hline União estável & 14 & 2,1 \\
\hline Casada (o) & 303 & 46,0 \\
\hline Divorciado (a)/desquitado (a)/separado (a) & 102 & 15,5 \\
\hline Solteiro (a) & 96 & 14,7 \\
\hline Viúvo (a) & 143 & 21,7 \\
\hline \multicolumn{3}{|c|}{$\begin{array}{l}\text { *Do total de processos investigativos, três não continham informações sobre a faixa etária; } \\
34 \text { casos não referiam à escolaridade e sete não tinham o registro de estado civil. } \\
\text { Fonte: Elaborada pelas autoras. }\end{array}$} \\
\hline \multicolumn{3}{|c|}{$\begin{array}{l}\text { Com relação ao perfil, verificou-se que há predomínio de mulhere } \\
(58,0 \%) \text {, na faixa etária de } 60 \text { a } 70 \text { anos }(53,9 \%) \text {, com ensino fundamental }(62,9 \%) \\
\text { casados } 46,0 \% \text { como demonstra a Tabela } 1 \text {. A média de idade dos pesquisados } \\
\text { foi } 71,23( \pm 7,43) \text {, mínimo de } 60 \text { e máximo de } 98 \text { anos. }\end{array}$} \\
\hline \multicolumn{3}{|c|}{$\begin{array}{l}\text { Tabela } 2 \text { - Distribuição das ocorrências, segundo a faixa etária e sexo dos idosos, vítimas } \\
\text { de violência. Santa Maria/RS, } 2015 .\end{array}$} \\
\hline Faixa etária & & Masculino \\
\hline $60-70$ & & $141(50,9 \%)$ \\
\hline $71-80$ & & $95(34,3 \%)$ \\
\hline $81-90$ & & $34(12,3 \%)$ \\
\hline $91-100$ & & $7(2,5 \%)$ \\
\hline Total & & 277 (100\%) \\
\hline
\end{tabular}

O teste qui-quadrado mostrou que não existiu relação significativa entre sexo e faixa etária $(p=0,290)$. Fonte: Elaborada pelas autoras. 
Com relação aos agressores, a Tabela 03 indica que a maior parte era do sexo masculino (65,2\%), na faixa etária de 40 a 60 anos (39,5\%), seguida daqueles com 25 a 39 anos (34,2\%). Destacou-se o fato de que $17,2 \%$ desses agressores também eram idosos. A idade média dos agressores foi de 44,42 $( \pm 14,99)$ anos, mínima de 16 e máxima de 93 anos. Houve predomínio dos casos de violência em que a vítima não possuía parentesco com o agressor, representando $51 \%$ das denúncias, como se evidencia na Tabela 3.

Tabela 3 - Distribuição dos agressores que praticaram violência contra os idosos, segundo sexo, faixa etária e sua relação com vítima de violência. Santa Maria/RS, 2015.

\begin{tabular}{|c|c|c|}
\hline Variáveis & $\begin{array}{c}\text { Frequência } \\
\text { Percentual (\%) }\end{array}$ & Percentual \% \\
\hline \multicolumn{3}{|l|}{ Sexo agressor } \\
\hline Feminino & 232 & 34,8 \\
\hline Masculino & 435 & 65,2 \\
\hline \multicolumn{3}{|l|}{ Faixa Etária (524) } \\
\hline$<25$ & 48 & 9,2 \\
\hline 25 a 39 & 179 & 34,1 \\
\hline 40 a 60 & 207 & 39,5 \\
\hline$\geq 60$ & 90 & 17,2 \\
\hline \multicolumn{3}{|c|}{ Relação do agressor com a vítima } \\
\hline Sem Parentesco & 353 & 51,0 \\
\hline Filho & 106 & 15,3 \\
\hline Parentes & 131 & 18,9 \\
\hline Filha & 46 & 6,6 \\
\hline Companheiro/esposo & 31 & 4,5 \\
\hline Outros* $^{\star}$ & 16 & 2,4 \\
\hline Companheira/esposa & 9 & 1,3 \\
\hline
\end{tabular}

* Cunhado(a), Enteado(a) e Ex-Cunhado(a).

Fonte: Elaborada pelas autoras.

A Tabela 4 mostra que o principal tipo de violência identificada nos processos investigativos foi de natureza psicológica (59,4\%). Essa categoria agrega os casos de injúria, ameaça, discriminação, desobediência e perturbação do sossego. As violências de natureza física corresponderam a 16,7\% dos casos, 
seguida da violência financeira ou material (13,8\%), abandono, maus-tratos e negligência, que corresponderam a 5,4\% dos registros. Dentre os tipos de violência, perpetradas contra idosos, a ameaça preponderou com $25,6 \%$ dos casos, acompanhada de lesão corporal $(11,40 \%)$, perturbação da tranquilidade $(11,00 \%)$, injúria $(8,90 \%)$ e estelionato $(7,40 \%)$.

Tabela 4 - Distribuição da frequência, segundo a natureza e o tipo de violência. Santa Maria/RS, 2015.

\begin{tabular}{|c|c|c|}
\hline Natureza da violência & Frequência & Percentual \% \\
\hline Psicológica & 395 & 59,4 \\
\hline Física & 111 & 16,7 \\
\hline Financeira ou material & 92 & 13,8 \\
\hline Abandono/maus tratos/negligência & 36 & 5,4 \\
\hline Outras fraudes/crimes* & 31 & 4,7 \\
\hline \multicolumn{3}{|l|}{ Tipo de violência } \\
\hline Ameaça & 170 & 25,60 \\
\hline Lesão corporal & 76 & 11,40 \\
\hline Perturbação da tranquilidade & 73 & 11,00 \\
\hline Injúria & 59 & 8,90 \\
\hline Outros crimes & 50 & 7,50 \\
\hline Estelionato & 49 & 7,40 \\
\hline Injúria qualificada & 36 & 5,40 \\
\hline Maus tratos contra o idoso & 31 & 4,60 \\
\hline Apropriação indébita de bem de idoso & 29 & 4,40 \\
\hline Vias de fato & 24 & 3,60 \\
\hline Perturbação do sossego alheio & 22 & 3,20 \\
\hline Desobediência & 15 & 2,30 \\
\hline Calúnia & 12 & 1,80 \\
\hline Dano & 10 & 1,50 \\
\hline Violação de domicílio & 9 & 1,40 \\
\hline
\end{tabular}

*Violências relativas a suicídio, falecimento, homicídio e desaparecimento de pessoa estão inseridos nesta classificação.

Fonte: Elaborada pelas autoras. 
Na Tabela 5, verificaram-se que existe associação entre a natureza da violência e sexo do idoso $(p=0,007)$, nos casos de violência financeira ou material, as mulheres foram mais acometidas do que os homens, com percentual de 17,6\%. Também, identificou-se que os homens tiveram percentual superior ao das mulheres em relação à violência física e psicológica 17,6\% e $63,1 \%$, respectivamente.

Tabela 5 - Distribuição da natureza da violência, segundo o sexo dos idosos. Santa Maria/RS, 2015.

\begin{tabular}{lcc}
\hline Natureza da violência & Feminino & Masculino \\
\hline Psicológica & $219(56,7 \%)$ & $176(63,1 \%)$ \\
Física & $62(16,1 \%)$ & $49(17,6 \%)$ \\
Financeira ou material & $68(17,6 \%)$ & $24(8,6 \%)$ \\
Abandono/maus tratos/negligência & $21(5,4 \%)$ & $15(5,4 \%)$ \\
Outras fraudes/crimes & $16(4,2 \%)$ & $15(5,3 \%)$ \\
Total & $386(100 \%)$ & $279(100 \%)$ \\
\hline
\end{tabular}

Fonte: Elaborada pelas autoras.

Os dados da Tabela 06 mostram que a violência psicológica predominou e foi praticada contra os idosos das faixas etárias 60 a 90 anos. Já para os idosos com idade entre 91 e 100 anos, o maior registro foi de abandono/maus-tratos/negligência em 45,5\% dos casos. A violência financeira ou material foi a segunda maior causa de registro para os idosos que estavam na faixa etária de 81 a 90 anos (26,0\%).

Tabela 6 - Distribuição da natureza da violência segundo faixa etária. Santa Maria/RS, 2015.

\begin{tabular}{lcccc}
\hline & \multicolumn{4}{c}{ Faixa Etária } \\
\hline Natureza da agressão & $60-70$ & $71-80$ & $81-90$ & $91-100$ \\
\hline Psicológica & $230(64,4 \%)$ & $134(60,6 \%)$ & $29(39,7 \%)$ & $2(18,2 \%)$ \\
Física & $67(18,8 \%)$ & $30(13,6 \%)$ & $13(17,8 \%)$ & $1(9,1 \%)$ \\
Financeira ou material & $33(9,2 \%)$ & $37(16,7 \%)$ & $19(26,0 \%)$ & $3(27,2 \%)$ \\
Abandono/maus tratos/negligência & $7(2,0 \%)$ & $14(6,3 \%)$ & $9(12,4 \%)$ & $5(45,5 \%)$ \\
Outras fraudes/crimes & $20(5,6 \%)$ & $6(2,8 \%)$ & $3(4,1 \%)$ & $0(0)$ \\
Total & 357 & 221 & 73 & 11 \\
\hline
\end{tabular}

Fonte: Elaborada pelas autoras. 
Nesta pesquisa, o predomínio de idosos, vítimas de violência, foi de mulheres casadas, na faixa etária de 60 a 70 anos, com ensino fundamental completo. Dados compatíveis aos de outros estudos (MASCARENHAS et al., 2012; OLIVEIRA et al., 2013; AGUIAR et al., 2015; RODRIGUES et al., 2017). O elevado percentual de pessoas idosas vítimas de violência, identificado nesta pesquisa, pode estar associado ao acelerado crescimento populacional deste segmento no Brasil, dado que tem sido confirmado por outros estudos sobre a temática (NOGUEIRA; FREITAS; ALMEIDA, 2011; DUQUE et al., 2012).

Para Aguiar et al. (2015), as pessoas que estão na faixa etária compreendida entre 60 e 70 anos ainda possuem maior autonomia funcional, conhecimento dos direitos dos idosos e possibilidades para efetivá-los em comparação aos mais velhos. Isto porque muitos dos idosos mais longevos já vivenciam processos de adoecimento incapacitantes, declínio cognitivo, dificuldades de mobilidade e crescente nível de dependência para a realização de atividades diárias, aspectos que devem ser considerados como dificultadores para a realização da denúncia, visto que essas situações tendem a mantê-los restritos ao ambiente doméstico. Entretanto, dois estudos encontraram valores discordantes, sendo as faixas etárias entre 70 a 89 anos de idade a mais prevalente de idosos vítimas de violência (NOGUEIRA; FREITAS; ALMEIDA, 2011; GUIMARÃES et al., 2016).

Em âmbito internacional, perfis semelhantes ao desta pesquisa também foram encontrados (ACIERNO et al., 2010; FRIEDMAN et al., 2011; THOMSON et al., 2011; DONG et al., 2014; SKIRBEKK; JAMES, 2014; GIL et al., 2015). Contudo, estudo desenvolvido em sete países da Europa identificou a ausência de registros de violência no sexo masculino, em virtude de normas sociais e culturais tradicionalmente machistas, que dificultam aos homens admitir o sofrimento da violência (MELCHIORRE et al., 2016).

No que se refere à escolaridade dos idosos vítimas de violência, o ensino fundamental prevaleceu, convergente aos achados de outras investigações (ACIERNO et al., 2010; THOMSON et al., 2011; OLIVEIRA et al., 2013; SKIRBEKK; JAMES, 2014; IRIGARAY et al., 2016). Na pesquisa de Aguiar et al. (2015), dos idosos que sofreram violência, apenas $4,4 \%$ cursaram o ensino superior. Quanto menor a escolaridade do idoso, maiores são as necessidades de auxílio para a administração financeira, o que pode favorecer e/ou aumentar a dependência familiar. A reduzida escolaridade identificada na pesquisa pode ser reflexo das condições sociais e culturais do século passado, quando a educação não se constituía em uma política pública e seu acesso era limitado, difícil e oneroso. Assim, como muitas famílias não tinham condições econômicas de manter os 
filhos estudando, era comum o abandono escolar precoce em detrimento da necessidade de participar das atividades domésticas e trabalho, contribuindo ativamente no sustento das famílias que, em geral, eram numerosas.

Para Irigaray (2016), baixa escolaridade e ausência de um companheiro são fatores de risco para a ocorrência de violência em idosos. Ainda, estudo identificou que idosos indianos com pelo menos oito anos de escolaridade apresentaram menor probabilidade de sofrer maus-tratos, pois possuíam nível crítico mínimo que os capacitava a reduzir ou evitar abusos (SKIRBEKK; JAMES, 2014).

Tendo em vista o perfil das vítimas de violência ser majoritariamente composto por mulheres, verificado neste e em outros estudos, isto em parte pode ser em função do processo de feminilização dos idosos brasileiros, em que as mulheres têm apresentado expectativa de vida maior frente aos homens. Além disso, a violência contra a mulher assume caráter geracional, pois desde jovem esta é uma ação incidente no cotidiano feminino, aumentando e/ou potencializando suas vulnerabilidades. Há maior vulnerabilidade da mulher idosa à violência, em especial, aquelas que já sofriam violência doméstica em idade adulta. Este fato exerce maior influência na ocorrência de maus-tratos que o risco de incapacidade decorrente da maior expectativa de vida (OLIVEIRA et al., 2013).

Soma-se a essa análise, o viés de gênero convergente a outros estudos realizados (PINHEIRO et al., 2011; DUQUE et al., 2012; GUIMARAES et al., 2016). A problemática da violência contra idosos, para além das questões geracionais, também segue uma lógica de gênero que se amálgama na cultura patriarcal que atribui papéis sociais de inferioridade e submissão às mulheres, o que se constitui em vulnerabilidades de gênero (CABRAL, 2014).

Neste estudo, entende-se vulnerabilidades de gênero como dispositivos que conferem materialidade a contextos determinados, baseados nas relações de poder e que invisibilizam e/ou naturalizam e essencializam desigualdades entre mulheres e homens (CABRAL, 2014). Nessa lógica, as vulnerabilidades de gênero remetem à compreensão de construções históricas, políticas, ideológicas, econômicas, sociais, culturais, relacionais e linguísticas entrelaçadas em torno dos papéis de gênero, dos mecanismos e instituições envolvidos com sua geração e que educam e (re)produzem homens e mulheres como "sujeitos de gênero" (CABRAL, 2014). As vulnerabilidades de gênero, que são conexas a outros marcadores sociais (como classe, etnia e raça) e que se inter-relacionam, de forma interdependente, à outras vulnerabilidades, incidem nos processos de saúde e adoecimento de idosos vítimas de violência, com potencial para atenuar algumas vulnerabilidades e acentuar e/ou produzir outras ao longo 
do tempo, uma vez que, dada sua dinamicidade, esse processo não é linear. Assim, a construção histórica e social das diferenças entre os sexos e das funções atribuídas para mulheres e homens produzem outras desigualdades em diferentes cenários, tais como no âmbito doméstico, conformando vulnerabilidades de gênero (CABRAL, 2014).

Um fator limitador deste estudo refere-se ao fato de que não há um formulário padronizado para os registros dos casos de violência. Por isso, na maioria das vezes, o local de ocorrência dos maus-tratos contra idosos não foi registrado. No entanto, a literatura nacional e internacional aponta o domicílio como o principal local de ocorrência de maus-tratos contra idosos (DUQUE et al., 2012; OLIVEIRA et al., 2013; SKIRBEKK; JAMES, 2014; IRIGARAY, 2016; RODRIGUES et al., 2017).

Na pesquisa de Friedman et al. (2011), 85,0\% dos agressores são parceiros íntimos ou familiares da pessoa idosa. Lachs e Pillemer (2016) argumentam que o fato de o agressor morar com o idoso representa o principal fator de risco para a ocorrência de maus-tratos. Estudo realizado em Havana verificou que $44,7 \%$ dos idosos eram vítimas de violência doméstica (RIBOT et al., 2015). Na mesma direção, pesquisa multicêntrica realizada no Canadá, Colômbia, Brasil e na Albânia com 1.995 idosos também reforçam essa questão (GUEDES et al., 2015).

Embora o domicílio seja o principal local de agressão à pessoa idosa, apontado na literatura, o mesmo nem sempre é reconhecido como potencial cenário para essa prática, devido à crença de o lar ser, por natureza, um local acolhedor, protetor e amoroso. Nesses casos, a relação intrafamiliar, geradora de conflitos se constitui em fator de risco, na medida em que expõe o idoso a violência de caráter velado pelos seus próprios constituintes vulnerabilizando ainda mais a pessoa idosa. Tal processo ocorre de modo que a ausência de proteção e segurança familiar, socialmente esperada, bem como o medo de represálias se configurem como justificativas para o silenciamento dos idosos vítimas de violência intrafamiliar, os quais tendem a não denunciá-los, devendo-se isso a elevada subnotificação (AGUIAR et al., 2015; GIL et al., 2015).

No contexto estudado, o estado civil predominante foi de casados ou em união estável (48,1\%), seguido de viúvos (21,7\%), divorciado/desquitado/ separado $(15,5 \%)$ e solteiros $(14,7 \%)$. Estudo realizado em Portugal verificou que mais da metade das vítimas era casada (GIL et al., 2015). Esse achado é corroborado por pesquisa que contou com a participação de 3.159 idosos chineses residentes em uma comunidade americana, segundo a qual também prevalece à violência contra mulheres casadas, associado a precárias condições de saúde. Outro achado que chama a atenção é o fato de que 9,1\% das idosas 
manifestaram que se sentiam desconfortáveis por conviverem com o agressor. Esses autores verificaram, também, associação entre o estado de saúde e a violência, indicando que apresentar uma debilitada condição de física aumenta o risco de sofrer violência (DONG et al., 2014). No estudo de Aguiar et al. (2015), houve predomínio da prática de violência em idosos viúvos, perfazendo $36,6 \%$ dos casos. Assim, possuir ou não parceiro fixo não exerce grande influência no acometimento do idoso por atos violentos, ou seja, a relação conjugal não representa maior proteção contra violências.

No que se refere ao sexo dos agressores desta pesquisa, a maioria era masculino (65,2\%), nas faixas etárias entre 40 e 60 anos (39,5\%) e 25 a 39 anos (34,2\%). Estudos apontam que violências foram praticadas particularmente por filhos, do sexo masculino, de meia-idade e que apresentaram interesse financeiro na vítima (MASCARENHAS et al., 2012; SKIRBEKK; JAMES, 2014; IRIGARAY, 2016).

Outro aspecto identificado pela pesquisa e que merece atenção refere-se ao fato de que $17,2 \%$ dos agressores denunciados nos processos investigativos também eram pessoas idosas. Essa constatação impõe a reflexão de que nem todos os idosos são frágeis, dependentes e indefesos. Muitos, a depender da idade, condição física e personalidade podem continuar manifestando reações de agressividade e produzir contextos violentos, especialmente seguindo a lógica de gênero.

Pesquisa realizada em Vitória da Conquista/Bahia corrobora os achados deste estudo, pois em 75\% das notificações de violência contra idosos analisadas, os agressores eram do sexo masculino (SILVA et al., 2017). O fato de os agressores serem majoritariamente homens se ancora numa perspectiva de gênero, em que a violência é reforçada por elementos da cultura que atribui a eles característica de força, poder e superioridade em relação às mulheres.

Outro agravante é o fato de as vítimas serem casados ou em união estável, $5,8 \%$ dos casos de violência registrados foram praticados por um dos cônjuges e, destes, 4,5\% foram pelo marido ou companheiro. Cabe demarcar que, no geral, os maus-tratos perpetrados na velhice por um dos cônjuges têm como base uma relação de violência repetitiva desde o início do relacionamento.

No estudo de Mascarenhas et al. (2012), houve diferença significativa na distribuição dos agressores segundo o sexo da vítima, em que as mulheres foram violentadas mais frequentemente por filhos e parceiros conjugais do que os homens. Estes, por sua vez, foram vítimas de pessoas desconhecidas e de seu círculo de convívio em maior proporção do que o observado entre as idosas.

Com relação aos agressores, verificou-se na pesquisa, que as violências perpetradas pelos filhos foram a segunda mais prevalente $(21,9 \%)$ e do sexo 
masculino (15,3\%). Esse dado é preocupante, pois os filhos geralmente são os entes mais próximos dos idosos e, segundo a Constituição Federal, são os responsáveis legais por amparar, ajudar e cuidar de seus pais na velhice, bem como de garantirem o direito à vida com dignidade (BRASIL, 1988).

Ainda, no âmbito familiar, a pesquisa identificou que $18,9 \%$ dos registros de violência analisados foram praticadas por parentes. Especificamente em relação ao agressor, investigações nacionais e internacionais apontam que, geralmente, é um familiar do idoso (FRIEDMAN et al., 2011; PINTO; BARHAM; ALBUQUERQUE, 2013; SKIRBEKK; JAMES, 2014).

A família é a fonte primária de interação, cuidado e aprendizagem ao longo do desenvolvimento e isso não muda na velhice. Na medida em que a idade avança costuma haver redução das interações sociais, o que implica em maior contato com os filhos e familiares mais próximos. Essa relação de proximidade tende a se intensificar quando o idoso tem sua independência prejudicada por doenças e incapacidades, quando os filhos costumam assumir a função de cuidadores diretos. Ainda, em muitas situações, a perda do cônjuge ou filho, adoecimento e/ou algum quadro de dependência podem fazer com que a pessoa idosa necessite residir com outros parentes.

A imposição dessa situação, em alguns casos, impacta na dinâmica da família e pode resultar negativamente tendo como desfecho situações de maus-tratos contra o idoso. Comumente, a violência praticada por familiares costuma ocorrer em virtude de conflitos intergeracionais, sobrecarga e estresse decorrentes das demandas do cuidado e por questões financeiras. Na mesma direção, Mascarenhas et al. (2012) argumentam que a maior frequência de situações de violência no domicílio, tanto entre homens como em mulheres idosas, pode ser devido ao choque de gerações, permeado por disputas de espaço físico e dificuldades financeiras na família (FREITAS; TEÓFILO, 2010). Situação semelhante foi encontrada na pesquisa de Aguiar et al. (2015), em que a maioria das agressões $(71,4 \%)$ foi praticada por parentes. Investigação portuguesa constatou que a maioria dos agressores pertencia à família nuclear, designadamente, cônjuges ou companheiros (atuais ou ex), filhos e enteados (GIL et al., 2015).

Quanto aos agressores sem parentesco com a pessoa idosa, esta categoria foi a prevalente no cenário estudado, atingindo $51 \%$ dos registros analisados. Nesse sentido, Irigaray et al. (2016) ampliam a discussão sobre a violência contra idosos praticadas em ambientes públicos, onde os estabelecimentos comerciais corresponderam a 9,6\% dos locais citados pelos denunciantes, seguido dos serviços de saúde e via pública, ainda que em menores percentuais. 
Esses agressores foram identificados nas denúncias como vizinhos, inquilinos comerciantes, atendentes de lojas, policiais, profissionais liberais como médicos e advogados e motorista de ônibus. Nogueira, Freitas e Almeida (2011) e Pinheiro et al. (2011) destacam que a maioria dos agressores era do sexo masculino e sem parentesco com a vítima, sendo que a agressão contra os idosos advinha de vizinhos, cuidadores, motoristas de ônibus, funcionários de estabelecimentos comerciais (lojas, banco, supermercados) e profissionais da saúde. Pinheiro et al. (2011) chamam atenção para o fato de ser mais fácil para a pessoa idosa denunciar um agressor com o qual não tem vínculos familiares, de parentesco e/ou afetivos.

No que tange ao tipo de agressão efetuada contra os idosos, estas foram registradas no boletim de ocorrência a partir do relato da vítima como: maus-tratos, ameaça, lesão corporal, perturbação da tranquilidade ou do sossego alheio, injúria qualificada ou não, estelionato, apropriação indébita de bem de idoso, vias de fato, desobediência, calúnia, violação de domicílio, dentre outros crimes. Um problema identificado se refere ao fato de que a tipologia da violência é registrada com base no relato da vítima e na percepção do profissional que acolhe essa denúncia, a qual tende a ser classificada na categoria mais grave ou contundente. Porém, verificou-se nos processos investigativos que muitas denúncias continham um conjunto de maus-tratos e violências que não são registradas e, por isso, não integram as estatísticas relativas à violência contra idosos. Essa subnotificação não possibilita uma compreensão maior desse fenômeno, seja nos âmbitos local, regional ou nacional, visto que não há uma padronização para tal.

Dentre os tipos de violência perpetradas contra os idosos, identificadas nos processos investigativos, a ameaça foi a prevalente para $25,6 \%$ dos casos, seguida de lesão corporal $(11,40 \%)$, perturbação da tranquilidade $(11,00 \%)$, injúria $(8,90 \%)$, outros crimes $(7,50 \%)$ e estelionato $(7,40 \%)$. Com relação à violência física, destaca-se que as denúncias foram por lesão corporal na pessoa idosa. Independentemente do tipo de violência, praticada no âmbito familiar ou não, seja um evento isolado ou recorrente. Assim, entende-se que o contexto afeta negativamente o processo de saúde do idoso com repercussões na sua qualidade de vida, além desse crime se configurar em violação aos direitos humanos e de cidadania.

Estudo aponta que os idosos com histórico de maus-tratos apresentaram maior prevalência de demência, depressão e problemas reumatológicos do que aqueles que não foram vitimizados (MARQUES; SOUZA, 2012). Nogueira, Freitas e Almeida (2011) apontaram que os idosos, independente da faixa etária, têm sido vítimas de diferentes tipos de violência: psicológica, física, 
econômica ou negligência. Estas situações são consideradas fortes preditores de transtornos psicológicos como depressão, ansiedade, autonegligência e de mortalidade (FRIEDMAN et al., 2011; DONG et al., 2011; MOSQUEDA; DONG, 2011; IRIGARAY et al., 2016). Assim, pode-se inferir que as condições de maus-tratos sofridas na velhice tendem a produzir vulnerabilidades ou, ainda, potencializar as já instituídas.

O manual de enfrentamento à violência contra a pessoa idosa chama a atenção para o fato de a violência psicológica ser a mais denunciada do que a física. Como a violência física é visível e deixa marcas no idoso, podem se constituir em prova em caso de denúncia, ser facilmente identificada e o agressor ser alvo de questionamentos. Talvez, por isso, a violência psicológica esteja sendo a mais praticada na medida em que sua comprovação seja dificultada por ser de ordem subjetiva (BRASIL, 2013).

Em relação à violência financeira ou material, verificou-se que existiu associação entre a sua natureza e o sexo do idoso, em que as mulheres foram mais acometidas do que os homens. Contudo, observou-se que os homens tiveram percentual superior ao das mulheres em relação à violência psicológica (63,1\%) e física $(17,6 \%)$. Na Europa, estudo apontou que houve prevalência da violência psicológica $(35,6 \%)$, seguida da financeira $(9,6 \%)$ e física $(2 \%)$ na população idosa, porém não realizaram diferenciação por sexo (LINDERT et al., 2012). No México, pesquisa com amostra de 8.894 idosos que registraram ocorrência de violência destacou a violência verbal $(62,9 \%)$, acompanhada da agressão física (32,3\%), sobretudo contra mulheres (18,7\%) (RUELAS-GONZÁLES et al., 2016). Em Portugal, estudo verificou que quase metade das vítimas (47,5\%) mencionou situações de violência financeira (GIL et al., 2015). O abuso financeiro/econômico $(38,2 \%)$ foi a segunda causa de violência sofrida pelos idosos na pesquisa de Guimarães et al. (2016), seguida da negligência (31,1\%) e violência física (12\%).

Investigação realizada em três municípios brasileiros verificou que, no município situado na região sudeste, o segundo tipo de violência mais frequente foi à física, e nos dois municípios do Nordeste, foi a financeira. Esses últimos achados são significativos por serem duas capitais cujas populações têm baixa renda, a maioria dos idosos recebe benefícios sociais e sofre esse tipo de problema, inclusive de membros de sua família (RODRIGUES et al., 2017).

Pinto, Barham e Albuquerque (2013) analisaram 712 prontuários de um serviço de disque-denúncia de uma cidade no interior de São Paulo e verificaram que a maioria dos casos envolvia negligência ou abandono $(85,0 \%)$ por parte dos familiares. A relação intrafamiliar geradora de conflitos expõe o idoso a contextos violentos, ainda que de caráter velado. Por isso, é fundamental que os profissionais de saúde estejam atentos para a identificação precoce 
de situações dessa natureza, pois, ao ser praticada por seus próprios entes, esses casos costumam ser pouco denunciados, devendo-se a isso a elevada subnotificação.

Estudos apontam diferentes motivos sobre o porquê de muitos idosos, vítimas de violência, não denunciarem seu agressor. Isto parece ocorrer por não perceberem o fenômeno como violência, pela manutenção da suposta união familiar, medo de incriminar seu filho, familiar ou parente próximo, receio de que as violências sejam agravadas pela denúncia, dependência do agressor, dificuldades de ir à delegacia, frágil rede de apoio e/ou ausência de acompanhamento social após a denúncia (SHIMBO; LABRONICI; MANTOVANI, 2011; MASCARENHAS et al., 2012; RODRIGUES et al., 2017).

No campo da saúde, a formação profissional, ainda com base no modelo biomédico, tende a priorizar necessidades restritas ao plano biológico, que compreende apenas um dos níveis do cuidado à saúde, aí incluídas as relativas à violência física. Seguindo essa lógica, situações de violências menos evidentes, tais como: a psicológica, a moral ou patrimonial, e que nem sempre produzem um quadro nosológico passível de intervenção pela clínica biomédica, costumam ser esvaziadas de sentido. A singularidade de demandas mais sutis como as dessa natureza, para que sejam captadas e acolhidas pelos serviços e equipes de saúde requerem a ampliação do horizonte normativo da relação cuidadora, na qual o cuidado em saúde é entendido como uma relação de encontro genuíno não só com o idoso, mas também com a família como unidade de cuidados.

\section{Conclusão}

Este estudo trouxe contribuições para a identificação do perfil da população idosa que sofre violência no município de Santa Maria/RS. Este é, em sua maioria, composto por mulheres, na faixa etária de 60-70 anos, com ensino fundamental e casadas. Já os agressores são, em geral, homens, com idade de 40 a 60 anos e sem parentesco com as vítimas.

Com o aumento do número de idosos e sua crescente visibilidade social, cada vez mais faz-se necessários novas pesquisas que enfoquem outros aspectos relativos à violência contra pessoas idosas, como por exemplo, que abordem perspectivas dos profissionais que acolhem essas denúncias nas delegacias de proteção ao idoso.

Vale ressaltar que o presente estudo teve como limitações: ter sido realizado com dados de boletins de ocorrência de apenas um município, o que 
pode não refletir a realidade da população geral; falta de padronização no registro das ocorrências; informações incompletas ou conflitantes numa mesma denúncia; muitos registros estavam quase apagados o que dificultou a leitura e coleta de algumas informações, principalmente aquelas relativas ao agressor e ao tipo de violência.

A violência contra a pessoa idosa é um problema de saúde pública, de ordem multifatorial, que aumenta de complexidade na medida em que se agregam outros marcadores, tais como: questões culturais, geracionais, de gênero, além de elementos relativos à vulnerabilidade social de idosos como situação econômica, aposentadoria, dependência ou não de cuidados com a saúde, rede familiar e social, dentre outros.

No campo da promoção da saúde, faz-se necessário que profissionais, gestores, conselhos de saúde, conselhos do idoso, instituições de ensino e sociedade civil conjuguem esforços para que as políticas públicas de proteção aos idosos sejam mais efetivas e eficazes, de modo a garantir um viver com saúde, qualidade e menos violento. Também é necessário a organização da rede de proteção a pessoa idosa articulada a setores como o da saúde e serviço social, de modo que ações conjuntas sejam organizadas, com vistas a prevenção da violência no contexto familiar e social, bem como de apoio as vítimas e suas famílias.

Para além do campo das políticas públicas de proteção a pessoa idosa, o enfrentamento da violência contra essa população, especialmente aquelas perpetradas no âmbito da família, requer ações intersetoriais e multiprofissionais: Para o poder público, sugere-se a criação de espaços de convivência e de cuidado para a permanência diurna do idoso; para as famílias, ações de apoio que ampliem a rede de cuidados para que a sobrecarga e os conflitos sejam minimizados; para os serviços e profissionais de saúde, é imperativo que a temática da violência integre a agenda das reuniões de equipe e, se necessário, as ações de educação permanente em serviço para sensibilização e maior conhecimento sobre a violência e suas diferentes tipologias, de modo que favoreçam sua prevenção, identificação precoce e notificação compulsória dos casos constatados; para a sociedade, em geral, a violência contra os idosos deve ser mais debatida com ênfase na psicológica, por ser a prevalente e, até mesmo, mais banalizada. Esse debate pode ocorrer em atividades de promoção da saúde, em ocasiões com a Semana do Idoso, já existente em muitos municípios, nos grupos de idosos, serviços de saúde, igrejas, centros comunitários, escolas, bancos, farmácias, dentre outros equipamentos sociais.

No âmbito da educação, que a temática da violência contra a pessoa idosa seja um tema transversal em todos os níveis de formação e não só no ensino 
superior, visto que essa complexa problemática atravessa as gerações e, como tal, deve ser abordada e prevenida por toda a sociedade.

\author{
CHARACTERIZATION OF CASES OF VIOLENCE \\ AGAINST ELDERLY PERSONS IN THE \\ MUNICIPALITY OF SANTA MARIA
}

\title{
abstract
}

This study aimed to characterize the cases of violence against the elderly in the city of Santa Maria/RS, which occurred during the year of 2014 through the collection of data found in police records of police protection to the elderly. It is a documented, descriptive, cross-sectional retrospective. Data were analyzed using SPSS software, version 15.0. It was found a superior number of female victims of aggression. The dominant age is between 60 and 70 years, the education that prevails is the elementary school, and most are married. In relation to the aggressors, it was found that the majority are male, age between 40 and 60 years with no family ties to the victims. The most practiced violence was a threat, followed by bodily harm and disturbing the peace. Thus, it can be seen that even with the guarantee of laws such as the Federal Constitution in 1988, the National Policy for the Elderly and the Elderly Statute that support the elderly, the situation of violence is still present. It needs to take steps to reverse this situation and promote aging well.

keywords

Elderly. Violence. Maltreatment in Elderly. Public Policy.

referências

ACIERNO, Ron et al. Prevalence and correlates of emotional, physical, sexual, and financial abuse and potential neglect in the United States: the national elder mistreatment study. American Journal of Public Health, Estados Unidos, v. 100, n. 2 , p. 292-297, Feb. 2010.

AGUIAR, Maria Pontes Campos et al. Violência contra idosos: descrição de casos no município de Aracaju, Sergipe, Brasil. Escola Anna Nery: Revista de Enfermagem, Rio de Janeiro, v. 19, n. 2, p. 343-349, 2015.

BRASIL. Constituição da República Federativa do Brasil. 18. ed. São Paulo: Editora Saraiva, 1988. 
BRASIL. Política Nacional do Idoso (PNI), promulgada pela Lei no 8.842. Lei no 8.842, de 4 de janeiro de 1994. Dispõe sobre a Política Nacional do Idoso, cria o Conselho Nacional do Idoso e dá outras providências. Brasília, DF: Diário Oficial da União, 4 jan. 1994.

BRASIL. Lei no 10.741, de 1 de outubro de 2003. Dispõe sobre o Estatuto do Idoso e dá outras providências. Brasília, DF: Diário oficial da União, 2003.

BRASIL. Ministério da Saúde. Estatuto do Idoso. 3. ed. 2. reimpr. Brasília, DF: Ministério da Saúde, 2013.

BRASIL. Portaria $n^{\circ}$ 2.528, de 8 de outubro de 2006. Aprova a Política Nacional de Saúde da Pessoa Idosa. Brasília, DF: Ministério da Saúde, 2006a.

BRASIL. Ministério da Saúde. Secretaria Executiva. Departamento de Apoio à Descentralização. Diretrizes operacionais dos Pactos pela Vida, em Defesa do SUS e de Gestão. Brasília, DF: Ministério da Saúde, 2006b.

BRASIL. Secretaria Especial dos Direitos Humanos. Plano de ação para o enfrentamento da violência contra a pessoa idosa. Brasília, DF: Secretaria Especial dos Direitos Humanos, 2007.

BRASIL. Conselho Nacional de Saúde. Resolução no 466, de 12 de dezembro de 2012. Brasília, DF: Ministério da Saúde, 2012.

BRASIL. Manual de enfrentamento à violência contra a pessoa idosa. É possível prevenir. É necessário superar. Texto de Maria Cecília de Souza Minayo. Brasília, DF: Secretaria de Direitos Humanos da Presidência da República, 2013.

CABRAL, Fernanda Beheregaray. Ciranda de Roses: vulnerabilidades, demandas e necessidades em saúde de trabalhadoras em assentamento rural. Tese (Doutorado em Enfermagem) - Escola Paulista de Enfermagem, Universidade Federal de São Paulo, São Paulo, 2014.

DONG, Xinqi et al. Prevalence and correlates of elder mistreatment in a community-dwelling population of US Chinese older adults. Journal Aging Health, v. 26, n. 7, p. 1209-1224, 2014.

DONG, Xinqi et al. Elder abuse and mortality: the role of psychological and social wellbeing. Gerontology, v. 57, n. 6, p. 549-558, 2011.

DUQUE, Andrezza Marques et al. Violência contra idosos no ambiente doméstico: prevalência e fatores associados (Recife/PE). Ciência e Saúde Coletiva, Rio de Janeiro, v. 17, n. 8, p. 2199-2208, ago. 2012.

FREITAS, Cibelly Aliny Siqueira Lima; TEÓFILO, Tiago José Silveira. Avaliação construtivista, sob uma abordagem integradora e intersetorial, das ações do Projeto Disque Idoso em Sobral (CE, Brasil). Ciência \& Saúde Coletiva, Rio de Janeiro, v. 15, n. 6, p. 2825-2833, set. 2010 .

FRIEDMAN, Lee S. et al. A case-control study of severe physical abuse of older adults. Journal of the American Geriatrics Society, Nova York, v. 5, n. 3, p. 417-422, Mar. 2011.

GIL, Ana Paula et al. Estudo sobre pessoas idosas vítimas de violência em Portugal: sociografia da ocorrência. Cadernos de Saúde Pública, Rio de Janeiro, v. 31, n. 6, 1234-1246, jun. 2015.

GUEDES, Dimitri Taurino et al. Socioeconomic status, social relations and domestic violence (DV) against elderly people in Canada, Albania Colombia and Brazil. Archives of Gerontology and Geriatrics, v. 60, n. 3, p. 492-500, May-June 2015.

GUIMARÃES, David Bernar Oliveira et al. Caracterização da pessoa idosa vítima de violência. Revista Enfermagem UFPE on-line, Recife, v. 10, supl. 3, p. 1343-1350, 2016.

IRIGARAY, Tatiana Quarti et al. Maus-tratos contra idosos em Porto Alegre, Rio Grande do Sul: um estudo documental. Estudos de Psicologia, Campinas, v. 33, n. 3, p. 543-551, 2016. 
LACHS, Mark; PILLEMER, Karl. Elder abuse. The New England Journal of Medicine, v. 373, n. 20, p. 1947-1956, 2015.

LINDERT, Jutta et al. Abuse and neglect of older persons in seven cities in seven countries in Europe: across-sectional community study. International Journal of Public Health, v. 58, n. 1, p. 121-132, Aug. 2012.

MARQUES, Filipa Daniela; SOUSA, Liliana. Integridade familiar: especificidades em idosos pobres. Paideia, Ribeirão Preto, v. 22, n. 52, p. 207-216, maio/ago. 2012.

MASCARENHAS, Márcio Dênis Medeiros et al. Violência contra a pessoa idosa: análise das notificações realizadas no setor saúde Brasil, 2010. Ciência \& Saúde coletiva, Rio de Janeiro, v. 17, n. 9, p. 2331-2341, 2012

MELCHIORRE, Maria Gabriella et al. Abuse of older men in seven european countries: a multilevel approach in the framework of an ecological model. PLoS One, Estados Unidos, v. 11, n. 1, e0146425, Jan. 2016

MOSQUEDA, Laura; DONG, Xinqi. Elder abuse and self-neglect: "I don't care anything about going to the doctor, to be honest...". JAMA, v. 306, n. 5, p. 532-540, Aug. 2011.

MUSSE, Juliana Oliveira; RIOS, Maria Helena Evangelista. Atuação do enfermeiro perante a violência doméstica sofrida pelo idoso. Estudos Interdisciplinares sobre Envelhecimento, Porto Alegre, v. 20, n. 2, p. 365-379, 2015

NOGUEIRA, Caroline Furtado; FREITAS, Maria Celia; ALMEIDA, Paulo Cesar. Violência contra idosos no município de Fortaleza, CE: uma análise documental. Revista Brasileira de Geriatria e Gerontologia, v. 14, n. 3, p. 543-554, 2011.

OLIVEIRA, Annelissa Andrade Virgínio et al. Maus-tratos a idosos: revisão integrativa da literatura. Revista Brasileira de Enfermagem, v. 66, n. 1, p. 128-133, jan./fev. 2013.

ORGANIZAÇÃO MUNDIAL DA SAÚDE (OMS). Relatório mundial sobre violência e saúde. Geneva: OMS, 2002.

PINHEIRO, Jeferson Souto et al. Perfil dos idosos que sofreram violência atendidos em uma instituição de Salvador no ano de 2008. Revista Baiana de Saúde Pública, Salvador, v. 35, n. 2, p. 264-276, abr./jun. 2011.

PINTO, Francine N. F. R.; BARHAM, Elizabeth Joan; ALBUQUERQUE, Paloma P. Idosos vitimas de violência: fatores sociodemográficos e subsídios para futuras intervenções. Estudos e Pesquisas em Psicologia, Rio de Janeiro, v. 13, n. 3, p. 1159-1181, 2013.

RIBOT, Victoria C. et al. Psychological the most common elder abuse in a Havana neighborhood. MEDICC Review, Estados Unidos, v. 17, n. 2, p. 39-43, Apr. 2015.

RODRIGUES, Rosalina Aparecida Partezani et al. Violência contra idosos em três municípios brasileiros. Revista Brasileira de Enfermagem, Brasília, DF, v. 70, n. 4, p. 816-824, jul./ago. 2017.

RUELAS-GONZÁLEZ, Maria Guadalupe et al. Prevalence and factors associated with violence and abuse of older adults in Mexico's 2012 National Health and Nutrition Survey. International Journal for Equity in Health, v. 15, n. 1, PMC4769586, 2016.

SHIMBO, Adriano Yoshio; LABRONICI, Liliana Maria; MANTOVANI, Maria de Fátima. Reconhecimento da violência intrafamiliar contra idosos pela equipe da estratégia saúde da família. Escola Anna Nery: Revista de Enfermagem, v. 15, n. 3, p. 506-510, jul./set. 2011.

SILVA, Adriene Reis et al. Violência contra idosos: associação entre o gênero dos agressores e o tipo de violência. Revista Multidisciplinar e de Psicologia, Brasil, v. 11, n. 38, p. 701-712, 2017. 
SILVA, Cirlene Francisca Sales da; DIAS, Cristina Maria de Souza Brito. Violência contra idosos: perfil sociodemográfico dos familiares agressores, tipos de violência impetrada e motivações para sua ocorrência. Revista Eletrônica de Gestão e Saúde, Brasília, DF, v. 7, n. 2, p. 563-581, 2016.

SKIRBEKK, Vegard; JAMES, Kumar S. Abuse against elderly in India: the role of education. BMC Public Health, v. 14, n. 336, p. 1-8, 2014.

SOUZA, Edinilsa Ramos de; MINAYO, Maria Cecília Souza. Inserção do tema violência contra a pessoa idosa nas políticas públicas de atenção à saúde no Brasil. Ciência \& Saúde Coletiva, Rio de Janeiro, v. 15, n. 6, p. 2659-2668, 2010.

THOMSON, Mary J. et al. An analysis of elder abuse rates in Milwaukee County. Wisconsin Medical Journal, Wisconsin, v. 110, n. 6, p. 271-276, Dec. 2011.

Data de Submissão: 15/05/2017

Data de Aprovação: 04/06/2020 
